BMJ Open

Sport \&

Exercise

Medicine

\title{
Physical activity during pregnancy and infant's birth weight: results from the 3D Birth Cohort
}

\author{
Michèle Bisson, ${ }^{1,2}$ Jordie Croteau, ${ }^{3}$ Benjamin C Guinhouya, ${ }^{4}$ Emmanuel Bujold, ${ }^{5}$ \\ François Audibert, ${ }^{6}$ William D Fraser, ${ }^{7}$ Isabelle Marc ${ }^{1}$
}

To cite: Bisson M, Croteau J, Guinhouya BC, et al. Physical activity during pregnancy and infant's birth weight: results from the 3D Birth Cohort. BMJ Open Sport Exerc Med 2017;3: 0000242. doi:10.1136/bmjsem-2017000242

\section{- Additional material is} published online only. To view please visit the journal online (http://dx.doi.org/10. 1136/bmjsem-2017000242)

Accepted 9 March 2017

\section{(a) CrossMark}

For numbered affiliations see end of article.

Correspondence to Dr Isabelle Marc; isabelle. marc@crchudequebec.ulaval. ca

\section{ABSTRACT}

Aim To evaluate the association between maternal physical activity and infant's birth weight or risk of inappropriate weight for gestational age (GA), and whether this association differs by infant's sex, maternal body mass index (BMI) or pregnancy complications in a prospective cohort study. Methods 1913 pregnant women from the 3D Birth Cohort (Québec, Canada) completed the Pregnancy Physical Activity Questionnaire at each trimester. Energy expenditure (metabolic equivalent of task (MET) *hours/week) for total activity, sports and exercise and vigorous intensity activities was calculated. The associations with birth weight and risk of inappropriate weight for GA were evaluated by regression modelling. Interactions were tested with infant's sex, maternal prepregnancy BMI, gestational diabetes, hypertensive disorders and prematurity.

Results Each $1 \mathrm{MET} /$ hours/week increase in sports and exercise in the first trimester was associated with a $2.5 \mathrm{~g}$ reduction in infant's birth weight $(95 \% \mathrm{Cl}-4.8$ to -0.3 ) but was not associated with the risk of small weight for GA. In contrast, although not significant, a $17 \%$ reduction in the risk of large weight for GA was observed with increasing sports and exercise.

Furthermore, in women with subsequent pre-eclampsia (but not normotensive or hypertensive women), each 1 $\mathrm{MET} /$ hours/week increment spent in any vigorous exercise in the first trimester reduced the infant's birth weight by $19.8 \mathrm{~g}(95 \% \mathrm{Cl}-35.2$ to -4.3$)$.

Conclusions Pregnant women with higher sports and exercise levels in the first trimester delivered infants with a lower birth weight. The risk of reducing infant's birth weight with vigorous exercise in women who develop pre-eclampsia later in pregnancy requires evaluation.

\section{INTRODUCTION}

Physical activity in pregnancy has been shown to influence perinatal outcomes. ${ }^{1-4}$ However, as physical activity parameters such as type, intensity and timing during pregnancy might exert different maternal and fetoplacental adaptations, ${ }^{5} 6$ the effects of various physical activity stimuli on birth weight need a thorough investigation.

\section{What are the new findings?}

Sports and exercise participation during the first trimester of pregnancy is associated with a reduced infant's birth weight.

- Sports and exercise participation during the first trimester of pregnancy is not associated with an increased risk of delivering a small for gestational age (GA) neonate but is rather associated with a near-significant $17 \%$ reduction in the risk of delivering a large for GA neonate.

- Practice of exercise at a vigorous intensity during the first trimesters is associated with a more pronounced reduction in infant's birth weight in women who go on to develop pre-eclampsia.

How might it impact on clinical practice in the near future?

Healthcare providers in charge of pregnant women can safely recommend sports and exercise practice in low-risk pregnancy as soon as the first months of pregnancy.

- In women at higher risk of pre-eclampsia, a closer follow-up of exercise practice in early pregnancy together with fetal growth might be required.

Moderate intensity exercise in early pregnancy has been shown to improve placental function in low-risk pregnancy, ${ }^{5} 7$ but in women who will develop a pregnancy complication, its impacts on fetal growth are unclear. Indeed, the effects of exercise on fetal growth remain unknown in pregnancies with endothelial dysfunction and abnormal perfusion or preterm birth. Other characteristics such as infant's sex and maternal body mass index $(\mathrm{BMI})^{8}$ may also modulate this association.

Furthermore, although moderate intensity physical activity seems relatively safe in uncomplicated pregnancies, ${ }^{9}$ there are 
concerns about vigorous exercise, as decreases in uteroplacental blood flow and transient fetal bradycardia have been observed following strenuous exercise. ${ }^{10-14}$ Yet, nearly $20 \%$ of pregnant women report performing vigorous exercise in early pregnancy. ${ }^{15}$

Using data from a large birth cohort, the objectives of this study were to evaluate the association between maternal physical activity, namely sports and exercise practice, vigorous exercise and total activity, and infant's birth weight or risk of inappropriate weight for gestational age (GA). We hypothesise that this association would differ according to infant's sex, maternal obesity status and the development of prematurity, gestational diabetes or hypertensive disorders of pregnancy.

\section{METHODS}

\section{Population and setting}

The 3D Birth Cohort recruited 2366 mother-fatherchild triads (singleton pregnancy) from 10 tertiary care centres in the province of Quebec from May 2010 to August 2012 (last delivery in 2013) with the primary aim of evaluating the impact of maternal anxiety on child's neurodevelopment at age 2. ${ }^{16}$ For the present study, analyses were performed in 1913 (81\%) pregnant women $(81 \%)$ recruited $<14$ weeks at recruitment. Reasons for exclusion $(n=453)$ were withdrawal from the study $(n=99)$, miscarriage or termination of pregnancy $(n=130)$, stillbirth $(n=5)$, missing birth weight $(n=41)$ or sex $(n=15)$ and insufficient physical activity data $(<20 \%$ of data, $n=163)$. Research ethics board of all involved institutions approved the study. All participants provided written informed consent for themselves and their infant. The study was reported according to the STROBE statement. ${ }^{17}$

\section{Design}

The 3D Birth Cohort collected extensive perinatal data, starting in the first trimester of pregnancy. Briefly, participating women were met between 8-13 ${ }^{6 /}$ ${ }^{7}$ weeks , between 20-24 ${ }^{6 / 7}$ weeks and between $32-34$ $6 / 7$ weeks of gestation by trained research assistants to collect sociodemographics, obstetrical and medical history during a structured interview. Perinatal history (ultrasound data, glucose tolerance tests, urine analyses) and pregnancy, delivery and neonatal outcomes were prospectively documented from medical charts. Women's weight, height and blood pressure were measured at each visit, whereas prepregnancy weight was recalled at the first visit. Participating fathers had height and weight measured at the first visit.

For the present study, the primary outcome was the infant's birth weight, collected from medical charts. Secondary outcomes included small and large birth weight for GA (SGA and LGA, respectively), defined as a birth weight adjusted for GA and sex $<10$ th and
$>90$ th percentile, respectively, based on Canadian reference values. ${ }^{18}$

Following each visit, women completed a web-based version of the Pregnancy Physical Activity Questionnaire (PPAQ), a questionnaire validated for pregnancy, ${ }^{19} 20$ to document their physical activity practice in the preceding month. Women reported the time (per day or week) they spent for each activity. Each activity was then assigned an intensity value in metabolic equivalent of task (MET, where 1 MET=energy expended at rest), based either on field measurements in pregnant women or on values found in the compendium of physical activity. ${ }^{19} 21$ This provided an energy expenditure for each activity expressed in MET*hours/week. Following this, total energy expenditure (total physical activity) was derived from all activities listed in the PPAQ, regardless of their context (ie, occupational, sports and exercise, transportation, household and care giving) or intensity (ie, sedentary, light, moderate and vigorous). Energy expenditure spent at sports and exercise was derived from activities of at least light intensity $(\geq 1.5$ METs) performed during leisure time. Finally, energy expenditure spent at vigorous intensity activities was also calculated by including leisure time activities with an intensity of $\geq 6$ METs (eg, jogging). These physical activity exposures were calculated for prepregnancy and for each trimester separately.

Sociodemographic, medical and lifestyle characteristics included maternal ethnicity, education, parity, household income, medication use, drugs and alcohol use, smoking, history of pregestational diabetes or hypertension and sleep habits (Pittsburgh Sleep Quality Index). ${ }^{22-24}$ Gestational diabetes diagnosis was based on biochemical analyses when available $(27 \%$, 2013 Canadian Diabetes Association criteria) ${ }^{25}$ or on diagnosis noted in medical charts. Gestational hypertension and pre-eclampsia were defined as hypertension first diagnosed during pregnancy (systolic blood pressure $\geq 140 \mathrm{~mm} \mathrm{Hg}$ and/or diastolic blood pressure $\geq 90 \mathrm{~mm} \mathrm{Hg}$, measured on two different occasions) and hypertension combined with proteinuria. ${ }^{26}$ GA at delivery was based on the first trimester ultrasound $(31 \%)$ or the date of the last menstrual period. ${ }^{27}$ Preterm birth was defined as delivery $<37$ weeks. Maternal prepregnancy BMI was calculated using self-reported prepregnancy weight and height measured at the first visit. ${ }^{28}$ Gestational weight gain was calculated by subtracting prepregnancy weight to the last recorded weight before delivery. Infant's birth length and sex were collected from medical charts.

\section{Statistical analyses}

All analyses were performed using SAS V.9.4. Data are presented as mean $\pm \mathrm{SD}$ or $\mathrm{n}(\%)$. Variations over time in maternal energy expenditure were analysed using paired t-tests with adjustment for multiple 
comparisons. Comparisons were restricted to consecutive measures (ie, first trimester vs prepregnancy, second vs first trimesters and third vs second trimesters).

Multiple regression modelling was used to estimate the effect of physical activity exposures on infant's birth weight. To assess the risk variation of LGA or SGA as a function of energy expenditure, relative risk (RR) estimates were calculated separately for each outcome using log-binomial regression. We also verified if there were statistical interactions with prepregnancy BMI category $(<18.5,18.5-24.9$, 25$29.9,>30 \mathrm{~kg} / \mathrm{m}^{2}$ ), infant's sex and pregnancy complications (gestational diabetes, gestational hypertension, pre-eclampsia and preterm birth). Gestational hypertension and pre-eclampsia were combined in the same models, further adjusted for hypertension prior to pregnancy. When the interaction was significant, results were presented for each stratum separately; otherwise, global results were presented.

Regression analyses were performed with and without adjustment variables. Variables were either selected from the literature (ie, maternal prepregnancy BMI, age, parity, smoking, drug use, education, ethnicity, prepregnancy physical activity and physical activity in other trimesters, infant's sex, GA at delivery and gestational weight gain) or if they caused $\geq 10 \%$ variation in the exposure coefficient in the crude model for at least one of the outcomes of interest (ie, study centre, paternal weight, history of diabetes prior to pregnancy and third trimester sleep score). GA, maternal prepregnancy BMI, weight gain, paternal weight, third trimester sleep score and physical activity were treated as continuous variables. Age was categorised as follows: <25, 25-35 and >35 years; education was dichotomised based on high school completion (yes/no); parity was categorised as 0,1 or $\geq 2$; ethnic groups were defined as Caucasian, multiethnic or other; drug use and smoking were categorised as current users, former users or nonusers; history of diabetes and of hypertension prior to pregnancy were dichotomised (yes/no). In order to limit overadjustment, gestational weight gain and physical activity in subsequent trimesters were tested as potential mediators using a SAS Macro. ${ }^{29}$

To reduce potential bias associated with missing data, a multiple imputation procedure ${ }^{30} 31$ based on the missing at random (MAR) assumption was applied, since all items used to calculate energy expenditure scores were not always answered. Indeed, composite scores of energy expenditure had non-observation rates of $18 \%-19 \%, 28 \%-44 \%$ and $33 \%-46 \%$ for the first, second and third trimesters, respectively. Twenty-five (25) imputed datasets were generated, and estimates from the 25 analysis replicates were combined to obtain a valid statistical inference. ${ }^{31}$ Baseline characteristics and pregnancy outcomes were presented using the non-imputed dataset.
To determine whether deviation from the MAR assumption could have biassed inferences, sensitivity analyses were performed. In addition to performing the analyses with the raw dataset, the following procedure was applied: (1) various percentiles $\mathrm{q}_{\mathrm{j}}(\mathrm{eg}, \mathrm{j}=10 \%$, $25 \%, 50 \%, 75 \%$ and $90 \%$ ) of energy expenditure in the raw dataset were calculated; (2) missing energy expenditure components were replaced by the $\mathrm{q}_{j}$ values and (3) the imputed data were used for confounders.

\section{RESULTS}

Main baseline characteristics and pregnancy outcomes are presented in tables 1 and 2. Characteristics of the entire 3D Birth Cohort can be found elsewhere. ${ }^{16}$ Compared with excluded women, included women were more likely to be Caucasian (72.8 vs $55.4 \%)$, nonsmoking (87.2 vs $82.9 \%$ ), primiparous ( 55.5 vs $48.3 \%$ ), have a lower prepregnancy BMI $(23.9 \pm 5.0$ vs $\left.24.5 \pm 5.4 \mathrm{~kg} / \mathrm{m}^{2}\right)$ and deliver at a later GA $(39.4 \pm 1.4 \mathrm{vs}$ $37.9 \pm 4.4$ weeks, all $\mathrm{p}<0.05)$. However, prepregnancy energy expenditure related to either total physical activity, sports and exercise or vigorous activities was similar.

Overall, maternal energy expenditure decreased from prepregnancy to late pregnancy (table 3). Vigorous exercise was reported by $35.5 \%, 31.4 \%$ and $18.6 \%$ of women during the first, second and third trimesters.

None of the potential mediators evaluated through mediation analysis had significant indirect effects in the association between maternal physical activity and birth weight. We thus included gestational weight gain and physical activity in subsequent trimesters as confounders in additional models.

In adjusted analyses, energy expenditure spent at sports and exercise during the first trimester was negatively associated with birth weight (table 4). According to adjusted model A, infants of women doing 11.7 METs*hours/week of sports and exercise (mean value in this cohort, equivalent to $\sim 3$ hour/week of brisk walking, ${ }^{21}$ which is slightly above current recommendations) compared with 0 MET*hours/week would experience a $29.72 \mathrm{~g}$ decrease in birth weight (95\% CI -55.88 to -3.50$)$. This association was however attenuated after adjustment for gestational weight gain (model B) and sports practice in subsequent trimesters $(-2.17 \mathrm{~g}$ per MET*hours/week, $95 \% \mathrm{CI}-4.60$ to $0.251)$.

The association between energy expenditure spent at vigorous exercise during the first trimester and birth weight differed by pre-eclampsia status ( $\mathrm{p}$ for interaction $=0.025$ and 0.023 in adjusted models $\mathrm{A}$ and $\mathrm{B}$, table 5), whereas it did not differ by gestational hypertension status ( $\mathrm{p}$ for interaction $=0.783$ and 0.625 in adjusted models $\mathrm{A}$ and $\mathrm{B}$, table 5). Among women who developed pre-eclampsia, each 1 MET*hours/week increase in vigorous exercise during the first trimester was associated with a $\sim 20 \mathrm{~g}$ decrease in birth weight. 
Table 1 Women's baseline characteristics

\begin{tabular}{|c|c|c|}
\hline Characteristic & $\mathbf{N}$ & $\begin{array}{c}\text { Mean } \pm \text { SD or } \\
\mathbf{n}(\%)\end{array}$ \\
\hline Study centre & 1913 & \\
\hline Montreal (8 centres) & & $1438(75.2)$ \\
\hline Quebec City & & $349(18.4)$ \\
\hline Sherbrooke & & $126(6.6)$ \\
\hline Age at first visit, year & 1908 & $31.4 \pm 4.5$ \\
\hline Prepregnancy BMI, kg/m² & 1808 & $23.9 \pm 5.0$ \\
\hline Underweight $(<18.5)$ & & $110(6.1)$ \\
\hline Normal weight (18.5-24.9) & & $1161(64.2)$ \\
\hline Overweight (25-29.9) & & $325(18.0)$ \\
\hline Obese $(\geq 30)$ & & $212(11.7)$ \\
\hline Gestational age at first visit, weeks & 1908 & $11.6 \pm 1.8$ \\
\hline Maternal ethnic origin & 1909 & \\
\hline Caucasian (white) & & $1389(72.8)$ \\
\hline $\begin{array}{l}\text { African-American, Asian, Hispanic, } \\
\text { First Nation }\end{array}$ & & $447(23.4)$ \\
\hline Multiethnic & & $73(3.8)$ \\
\hline Education: completed high school & 1899 & $1867(98.3)$ \\
\hline $\begin{array}{l}\text { Marital status: married or living with a } \\
\text { partner }\end{array}$ & 1911 & $1816(95.0)$ \\
\hline $\begin{array}{l}\text { Working before pregnancy (full time or } \\
\text { part time) }\end{array}$ & 1911 & $1569(82.1)$ \\
\hline Household income $\geq \$ 60000$ per year & 1830 & $1294(70.7)$ \\
\hline Parity (Para) & 1912 & \\
\hline 0 & & $1062(55.5)$ \\
\hline 1 & & $624(32.6)$ \\
\hline$\geq 2$ & & $226(11.9)$ \\
\hline Smoking status & 1860 & \\
\hline Non-smoker (never smoked) & & $1247(67.0)$ \\
\hline Ex-smoker & & $375(20.2)$ \\
\hline Smoked during first trimester & & $238(12.8)$ \\
\hline History of drug use & 1909 & \\
\hline Used or tried before pregnancy & & $1005(52.7)$ \\
\hline Used or tried during first trimester & & $46(2.4)$ \\
\hline Never tried & & $858(44.9)$ \\
\hline \multicolumn{3}{|l|}{ Medical history } \\
\hline Pregestational diabetes & 1907 & $10(0.5)$ \\
\hline Pregestational hypertension & 1902 & $20(1.1)$ \\
\hline Paternal weight at visit $1, \mathrm{~kg}$ & 1450 & $83.8 \pm 15.0$ \\
\hline
\end{tabular}

Data are presented without imputation for missing values.
This is equivalent to a $61.26 \mathrm{~g}$ reduction $(95 \% \mathrm{CI}$ -109.23 to -13.26 ) for an energy expenditure of 3.1 METs*hours/week (mean value in this cohort, equivalent to $\sim 30 \mathrm{~min} /$ week of light jogging ${ }^{21}$ ). This association persisted even after adjustment for vigorous exercise practice in subsequent trimesters $(-19.7 \mathrm{~g}$ per MET*hours/week, 95\% CI -35.23 to -4.20 ).

The association between physical activity exposures and birth weight did not differ by infant's sex, maternal prepregnancy BMI, prematurity or diabetes status. There were no associations between second or third trimester physical activity exposures and infant's birth weight.

Finally, no association was observed with the occurrence of SGA or LGA, with the exception of a nearsignificant reduction in the risk of LGA (adjusted model B, RR 0.83 , 95\% CI 0.67 to 1.02 ) found with increasing energy expenditure spent at sports and exercise during the first trimester (table 6). No interactions were detected in the evaluation of the risk for SGA or LGA.

\section{Sensitivity analyses}

Sensitivity analyses using the raw dataset (without missing data, $n=809-821$ ) resulted in consistent findings for the associations between first trimester sports and exercise and birth weight $(-2.66 \mathrm{~g}$ per MET*hours/week, $p=0.075)$, and between first trimester vigorous exercise and birth weight in women with pre-eclampsia $(-25.72 \mathrm{~g}$ per MET*hours/week, $\mathrm{p}=0.007)$. When replacing missing physical activity components by predetermined percentiles, the association between sports and exercise during the first

\section{Table 2 Pregnancy outcomes}

\begin{tabular}{lcc}
\hline Characteristic & N & $\begin{array}{c}\text { Mean } \pm \text { SD or } \mathbf{~} \\
\text { (\%) }\end{array}$ \\
\hline $\begin{array}{l}\text { Gestational age at delivery, } \\
\text { weeks }\end{array}$ & 1913 & $39.4 \pm 1.4$ \\
\hline $\begin{array}{l}\text { Preterm delivery (<37 weeks) } \\
\text { Gestational weight gain, kg }\end{array}$ & 1913 & $106(5.5)$ \\
\hline Gestational diabetes & 1910 & $14.3 \pm 5.4$ \\
\hline $\begin{array}{l}\text { Hypertensive disorders of } \\
\text { pregnancy }\end{array}$ & 1913 & $193(10.1)$ \\
\hline \multicolumn{1}{|c}{ Gestational hypertension } & & $116(6.1)$ \\
\hline \multicolumn{1}{|c}{ Pre-eclampsia } & 1913 & $3376.1 \pm 488.0$ \\
\hline Birth weight, g & 1913 & $965(50.4)$ \\
\hline Male sex & 1729 & $51.1 \pm 2.4$ \\
\hline Birth length, cm & 1913 & $141(7.4)$ \\
\hline Large for gestational age & 1913 & $161(8.4)$ \\
\hline Small for gestational age & & $77.0)$ \\
\hline
\end{tabular}

Data are presented without imputation for missing values. 
Table 3 Physical activity participation from the Pregnancy Physical Activity Questionnaire

\begin{tabular}{lcccc}
\hline $\begin{array}{l}\text { Mean } \pm \text { SD* } \\
\text { in MET*hours/week }\end{array}$ & Prepregnancy & First trimester & Second trimester & Third trimester \\
\hline Total energy expenditure & $266.1 \pm 0.7$ & $215.8 \pm 0.5^{\dagger}$ & $192.6 \pm 1.3^{\dagger}$ & $186.9^{\dagger} \pm 1.8^{\ddagger}$ \\
\hline By intensity & & & & $46.9 \pm 0.6$ \\
\hline Sedentary & $75.8 \pm 0.3$ & $73.9 \pm 0.3$ & $47.4 \pm 0.4$ & $90.3 \pm 0.9$ \\
\hline Light & $95.5 \pm 0.3$ & $77.9 \pm 0.3$ & $88.8 \pm 1.0$ & $48.3 \pm 0.7$ \\
\hline Moderate & $87.6 \pm 0.5$ & $60.9 \pm 0.5$ & $54.2 \pm 0.5$ & $1.4 \pm 0.03^{\dagger}$ \\
\hline Vigorous & $7.2 \pm 0.08$ & $3.1 \pm 0.05^{\dagger}$ & $2.3 \pm 0.05^{\dagger}$ & \\
\hline By type & & & $91.8 \pm 0.9$ & $91.5 \pm 0.9$ \\
\hline Household/care giving & $89.1 \pm 0.4$ & $72.7 \pm 0.4$ & $25.4 \pm 0.8$ & $19.8 \pm 0.7$ \\
\hline Occupational activity & $103.0 \pm 0.5$ & $85.8 \pm 0.6$ & $12.5 \pm 0.1^{\ddagger}$ & $11.8 \pm 0.1^{\ddagger}$ \\
\hline Sports and exercise & $18.4 \pm 0.1$ & $11.7 \pm 0.1^{\dagger}$ & $30.9 \pm 0.5$ & $30.0 \pm 0.5$ \\
\hline Transportation & $29.0 \pm 0.2$ & $23.5 \pm 0.1$ & & \\
\hline
\end{tabular}

*Mean of the 25 imputed datasets.

$\dagger$ Different from preceding period at $p<0.0001$ (with Bonferroni correction).

$\ddagger$ Different from preceding period at $\mathrm{p}<0.05$ (with Bonferroni correction).

$\S$ Excluding women not working/studying/doing voluntary work $(n=1563-1749)$.

MET, metabolic equivalent of task.

trimester and birth weight remained similar, as did the association between first trimester vigorous exercise and birth weight in the pre-eclampsia stratum (see online supplementary tables 1 and 2).

\section{DISCUSSION}

\section{Main findings}

In this large pregnancy cohort, women with a higher sports and exercise energy expenditure during the first trimester delivered infants with a reduced birth weight without evidence for an increased risk for SGA. We also observed a near-significant reduction in the risk of LGA with increasing exercise levels in the first trimester. Interestingly, women who performed vigorous exercise in the first trimester and further developed preeclampsia in later pregnancy delivered infants with a smaller birth weight, an association not found in normotensive women or women with gestational hypertension. Our findings highlight that maternal exercise in early pregnancy might be an important determinant of fetal growth, although physical activity in the later stages of pregnancy might also play a role.

\section{Interpretation}

In the present study, inverse associations between maternal energy expenditure and birth weight were all detected in the first trimester, independently from prepregnancy physical activity. Other evidence also suggests that the first trimester might be a sensitive period for fetal growth programming, with excessive weight gain during the first half of pregnancy associated with increased neonatal weight and adiposity. ${ }^{32}$ We also recently reported that vigorous physical activity assessed by accelerometry in the first half of pregnancy was an independent predictor of neonatal adiposity, regardless of subsequent physical activity $_{\text {practice. }}{ }^{33}$ Thus, beyond an effect on birth weight, maternal physical activity in early pregnancy may also influence infant's body composition, which may have a long-term beneficial impact on childhood obesity risk. ${ }^{34}$ Despite reducing birth weight, first trimester sports and exercise was not associated with an increased risk of SGA, which is reassuring and consistent with previous reports. ${ }^{1}$ Moreover, our study and others ${ }^{35}{ }^{36}$ suggest a reduction in the risk of large infants with maternal exercise.

The observed association between exercise and birth weight appeared partially dependent on gestational weight gain. Indeed, physical activity interventions can reduce gestational weight gain, ${ }^{3}$ whereas excessive gestational weight gain has been associated with the risk of delivering a larger neonate. ${ }^{37}$ Epigenetic mechanisms could also be involved, as total energy expenditure in early pregnancy has been associated with a reduced cord blood DNA methylation of the PLAGL1 gene, ${ }^{38}$ whose methylation level is positively associated with fetal growth. ${ }^{39}$ Methylation of this imprinted gene might mediate the association between maternal physical activity and birth weight, as it attenuates this association. ${ }^{38}$

An interesting finding in our cohort is the association between first trimester vigorous exercise energy 
Table 4 Overall associations between maternal physical activity (in MET*hours/week) and infant's birth weight (g)

\begin{tabular}{|c|c|c|c|c|c|c|c|c|c|}
\hline \multirow[b]{2}{*}{$\begin{array}{l}\text { Per MET*hours/ } \\
\text { week } \\
\quad \text { Estimate }\end{array}$} & \multicolumn{3}{|c|}{ Crude model } & \multicolumn{3}{|c|}{ Adjusted model A* } & \multicolumn{3}{|c|}{ Adjusted model $\mathrm{B}^{\dagger}$} \\
\hline & \multicolumn{3}{|c|}{$\begin{array}{l}\text { Estimate } \\
\text { p Value }\end{array}$} & $95 \% \mathrm{Cl}$ & \multicolumn{2}{|l|}{ p Value } & Estimate & $95 \% \mathrm{Cl}$ & $\begin{array}{c}\mathbf{p} \\
\text { Value }\end{array}$ \\
\hline \multicolumn{10}{|c|}{ Total energy expenditure } \\
\hline First trimester & 0.23 & -0.02 to 0.49 & 0.076 & -0.23 & -0.54 to 0.09 & 0.154 & -0.18 & -0.49 to 0.13 & 0.263 \\
\hline $\begin{array}{l}\text { Second } \\
\text { trimester }\end{array}$ & 0.46 & 0.10 to 0.83 & 0.014 & -0.01 & -0.43 to 0.41 & 0.947 & -0.02 & -0.43 to 0.38 & 0.904 \\
\hline Third trimester & 0.49 & 0.10 to 0.88 & 0.015 & -0.01 & -0.52 to 0.51 & 0.972 & -0.06 & -0.58 to 0.45 & 0.812 \\
\hline \multicolumn{10}{|c|}{ Sports and exercise } \\
\hline First trimester & -1.19 & -3.18 to 0.80 & 0.243 & -2.54 & -4.78 to 0.30 & 0.027 & -2.20 & -4.42 to 0.01 & 0.051 \\
\hline $\begin{array}{l}\text { Second } \\
\text { trimester }\end{array}$ & -0.83 & -2.93 to 1.27 & 0.437 & -0.56 & -2.90 to 1.78 & 0.639 & -0.27 & -2.54 to 1.99 & 0.814 \\
\hline Third trimester & -0.91 & -3.42 to 1.59 & 0.475 & 0.41 & -2.41 to 3.23 & 0.776 & 0.34 & -2.44 to 3.12 & 0.811 \\
\hline \multicolumn{10}{|c|}{ Vigorous exercise } \\
\hline First trimester & -0.69 & -4.16 to 2.78 & 0.695 & -2.64 & -6.17 to 0.89 & 0.142 & -2.07 & -5.53 to 1.38 & 0.239 \\
\hline $\begin{array}{l}\text { Second } \\
\text { trimester }\end{array}$ & 0.08 & -4.25 to 4.41 & 0.972 & 0.07 & -4.26 to 4.40 & 0.973 & 0.69 & -3.59 to 4.96 & 0.753 \\
\hline Third trimester & 0.29 & -6.36 to 6.95 & 0.931 & -1.87 & -8.18 to 4.44 & 0.562 & -1.12 & -7.31 to 5.07 & 0.723 \\
\hline
\end{tabular}

*Adjusted for gestational age at delivery, infant's sex, study centre, maternal prepregnancy BMI, age, education, ethnicity, parity, drug use, smoking, paternal weight, history of diabetes, third trimester sleep score, physical activity prior to pregnancy and in a previous trimester, where applicable.

$\dagger$ Adjusted for variables of model A plus gestational weight gain.

MET, metabolic equivalent of task.

expenditure with a non-negligible decreased birth weight in infants born to pre-eclamptic women. As preeclampsia can be associated with impaired placentation and uteroplacental circulation, ${ }^{40}$ it is possible that the insufficient placenta of these women cannot adapt sufficiently to the stress produced by vigorous exercise, leading to a reduction, although relatively small, in fetal growth. In support of this hypothesis, a previous study evaluating the acute effect of a cycling session on uteroplacental blood flow suggested a greater increase in the resistance index in pregnant women with pregnancy complications including pre-eclampsia compared with controls. ${ }^{41}$ Another group compared the umbilical artery pulsatility index response to

Table 5 Associations between vigorous exercise during first trimester and infant's birth weight according hypertensive disorder status

\begin{tabular}{|c|c|c|c|c|c|c|}
\hline \multirow[b]{2}{*}{ Per 1 MET*hours/week increase } & \multicolumn{3}{|c|}{ Adjusted model $\mathrm{A}^{\star^{\dagger}}$} & \multicolumn{3}{|c|}{ Adjusted model $\mathbf{B}^{\ddagger \S}$} \\
\hline & Estimate & $95 \% \mathrm{Cl}$ & p Value & Estimate & $95 \% \mathrm{Cl}$ & p Value \\
\hline Pre-eclampsia $(n=77)$ & -20.57 & -36.50 to -4.65 & 0.011 & -19.76 & -35.24 to -4.28 & 0.012 \\
\hline Gestational hypertension $(n=116)$ & -0.28 & -13.64 to 13.08 & 0.967 & 1.63 & -11.50 to 14.76 & 0.808 \\
\hline No hypertensive disorder $(n=1720)$ & -2.19 & -5.82 to 1.44 & 0.238 & -1.69 & -5.23 to 1.86 & 0.350 \\
\hline
\end{tabular}

*Adjusted for gestational age at delivery, infant's sex, study centre, maternal prepregnancy BMI, age, education, ethnicity, parity, drug use, smoking, paternal weight, history of diabetes prior to pregnancy, third trimester sleep score, physical activity prior to pregnancy, interaction between hypertensive disorder and physical activity, and history of hypertension prior to pregnancy. $\dagger p=0.025$ for the interaction between first trimester vigorous physical activity and pre-eclampsia status.

$\ddagger$ Adjusted for gestational age at delivery, infant sex, study centre, maternal prepregnancy BMI, age, education, ethnicity, parity, drug use, smoking, paternal weight, history of diabetes prior to pregnancy, third trimester sleep score, physical activity prior to pregnancy, interaction between hypertensive disorder and physical activity, history of hypertension prior to pregnancy and gestational weight gain. $\S p=0.023$ for the interaction between first trimester vigorous physical activity and pre-eclampsia status.

MET, metabolic equivalent of task. 
Table 6 Associations between first trimester sports and exercise and risk of small and large birth weight for gestational age

\begin{tabular}{|c|c|c|c|c|c|c|c|c|c|}
\hline \multirow{2}{*}{$\begin{array}{l}\text { Per } 10 \text { METs*hours/week } \\
\text { increase }\end{array}$} & \multicolumn{3}{|c|}{ Crude model } & \multicolumn{3}{|c|}{ Adjusted model A* } & \multicolumn{3}{|c|}{ Adjusted model $\mathrm{B}^{\dagger}$} \\
\hline & $\mathbf{R R}$ & $95 \% \mathrm{Cl}$ & p Value & RR & $95 \% \mathrm{Cl}$ & p Value & $\mathbf{R R}$ & $95 \% \mathrm{Cl}$ & p Value \\
\hline $\begin{array}{l}\text { Small weight for gestational } \\
\text { age }\end{array}$ & 1.03 & $\begin{array}{c}0.91 \\
\text { to } 1.17\end{array}$ & 0.675 & 1.03 & $\begin{array}{c}0.84 \\
\text { to } 1.25\end{array}$ & 0.788 & 1.02 & $\begin{array}{l}0.84 \\
\text { to } 1.25\end{array}$ & 0.845 \\
\hline $\begin{array}{l}\text { Large weight for gestational } \\
\text { age }\end{array}$ & 0.84 & $\begin{array}{l}0.71 \\
\text { to } 0.99\end{array}$ & 0.038 & 0.82 & $\begin{array}{l}0.66 \\
\text { to } 1.01\end{array}$ & 0.062 & 0.83 & $\begin{array}{l}0.67 \\
\text { to } 1.02\end{array}$ & 0.077 \\
\hline
\end{tabular}

*Adjusted for study centre, maternal prepregnancy BMI, age, education, ethnicity, parity, drug use, smoking, paternal weight, history of diabetes prior to pregnancy, third trimester sleep score and physical activity prior to pregnancy.

$\dagger$ Adjusted for study centre, maternal prepregnancy BMI, age, education, ethnicity, parity, drug use, smoking, paternal weight, history of diabetes prior to pregnancy, third trimester sleep score, physical activity prior to pregnancy and gestational weight gain.

MET, metabolic equivalent of task; RR, relative risk.

submaximal exercise in women with uteroplacental vascular insufficiency (UPVI; of which half developed pre-eclampsia) and healthy pregnant women. $^{42}$ Following exercise, the pulsatility index increased in the UPVI group, whereas it decreased in the control group, and three women from the UPVI group developed transient absent end diastolic flow. These studies suggest that suboptimal perfusion might occur with exercise in women who go on to develop preeclampsia, contributing to a decreased fetal growth. Our finding indicates that subtle exercise-induced perfusion modifications could occur even before clinical signs of the disease are observed. However, whether this decrease in birth weight is detrimental for the fetus of pre-eclamptic women remains to be established, as we might not have had sufficient power to evaluate the risk of SGA in this subsample. Previous reviews also indicate that physical activity in early pregnancy might help preventing pre-eclampsia, although evidence is still mitigated. ${ }^{43-45}$ Accordingly, since vigorous exercise seems quite prevalent in early pregnancy (30\% in this cohort) and since its effects remain poorly described, more studies are needed before any recommendations can be made.

\section{Methodological considerations}

The strengths of the present study include the prospective evaluation of physical activity during each trimester of pregnancy using a validated questionnaire. The detailed characterisation of participants and outcomes based on standardised criteria also allowed the study of physical activity during pregnancy while considering characteristics for which the effects of physical activity have been poorly described.

Our study has some limitations. First, our results might not be generalisable to all pregnant populations. Indeed, women included in the study were mostly Caucasians and of high socioeconomic status. Women with a higher physical activity practice might also have been more prone to complete the PPAQ. Second, an overestimation of physical activity or misclassification of intensity is possible with selfreport. However, data derived from the PPAQ correlate with acceptable accuracy with objective data obtained by accelerometry during pregnancy, ${ }^{19} 20$ despite a possible overestimation. ${ }^{46}$ To establish the precise effects of various physical activity intensities and levels on birth weight, future cohorts should nevertheless use objective measures of physical activity such as accelerometry. As with any observational studies, the observed associations may not represent cause-effect relationships. However, our results are consistent with previous meta-analyses of randomised trials ${ }^{1}{ }^{4}$ while providing additional information regarding the impact of exercise intensity and timing on the association with birth weight. Finally, our dataset had a relatively high proportion of missing values, with missing physical activity data increasing over time. However, the use of a multiple imputation procedure might be preferable in terms of results validity than complete case analysis only. ${ }^{47}$ Additionally, sensitivity analyses comforted our findings. Accordingly, we believe our results remain noteworthy.

\section{CONCLUSION}

A decreased birth weight without detrimental effects on birth weight extremes with sports and exercise practice in the first trimester reinforces exercise guidelines and underlines the importance of exercise in the early months of pregnancy. Although vigorous exercise might still be adequate for some women, the need for an 'upper safety limit' should be clarified given its potential effects on pregnancy outcomes and its apparently high prevalence in early pregnancy.

\section{Author affiliations}

${ }^{1}$ Department of Pediatrics, CHU de Qubec, Québec City, Canada

${ }^{2}$ Department of Kinesiology, Université Laval, Québec City, Canada

${ }^{3}$ Laboratory of Biostatistics, Centre de recherche de I'Institut universitaire en sante mentale de Quebec, Quebec, Canada

${ }^{4}$ Laboratory of Public Health, Universite de Lille II, Lille, France

${ }^{5}$ Department of Obstetrics and Gynecology, CHU de Québec, Québec City, Canada 
${ }^{6}$ Department of Obstetrics and Gynecology, Centre Hospitalier Universitaire Sainte-Justine, Montreal, Québec, Canada

${ }^{7}$ Department of Obstetrics and Gynecology, Universite de Sherbrooke, Sherbrooke, Canada

Acknowledgements This project was conducted as part of the research programme of the Integrated Research Network in Perinatology of Quebec and Eastern Ontario (IRNPQE0). The authors thank all the recruiting centres involved in this study, and Dr Alexandre Bureau, professor at the Department of Social and Preventive Medicine, Université Laval, for statistical support and revision of the statistical methods and interpretation.

Contributors WDF is the principal investigator for the 3D Birth Cohort and IM was in charge of the physical activity assessment. WDF, IM, EB and FA supervised data collection. IM, MB and JC developed the study hypotheses, and planned and performed data analyses. $\mathrm{MB}$ and $\mathrm{IM}$ wrote the original draft, and all the authors (BCG, WDF, EB, FA, JC) commented on the draft, contributed to the interpretation of the findings and had final approval of the submitted version.

Funding This work was supported by the Canadian Institutes of Health Research [CRI 88413]. MB is supported by a doctoral scholarship from the Canadian Institutes of Health Research. The funder had no role in study design; in the collection, analysis and interpretation of data; in the writing of the report; and in the decision to submit the article for publication.

Competing interests None declared.

Ethics approval The Research Ethics Board of the Centre de recherche du Centre hospitalier universitaire Sainte-Justine approved the initial protocol (reference number CHU-HSJ-2009-010) on 19 April 2010.

Provenance and peer review Not commissioned; externally peer reviewed.

Open Access This is an Open Access article distributed in accordance with the Creative Commons Attribution Non Commercial (CC BY-NC 4.0) license, which permits others to distribute, remix, adapt, build upon this work noncommercially, and license their derivative works on different terms, provided the original work is properly cited and the use is non-commercial. See: http:// creativecommons.org/licenses/by-nc/4.0/

Correction notice This paper has been amended since it was published Online First. Owing to a scripting error, some of the publisher names in the references were replaced with 'BMJ Publishing Group'. This only affected the full text version, not the PDF. We have since corrected these errors and the correct publishers have been inserted into the references.

(C) Article author(s) (or their employer(s) unless otherwise stated in the text of the article) 2017. All rights reserved. No commercial use is permitted unless otherwise expressly granted.

\section{REFERENCES}

1. Wiebe HW, Boulé NG, Chari R, et al. The effect of supervised prenatal exercise on fetal growth: a meta-analysis. Obstet Gynecol 2015;125:1185-94.

2. Russo LM, Nobles C, Ertel KA, et al. Physical activity interventions in pregnancy and risk of gestational diabetes mellitus: a systematic review and meta-analysis. Obstet Gynecol 2015;125:576-82.

3. Sanabria-Martínez G, García-Hermoso A, Poyatos-León R, et al. Effectiveness of physical activity interventions on preventing gestational diabetes mellitus and excessive maternal weight gain: a meta-analysis. BJOG 2015;122:1167-74.

4. Sanabria-Martínez G, García-Hermoso A, Poyatos-León R, et al. Effects of exercise-based interventions on neonatal outcomes: a meta-analysis of randomized controlled trials. Am J Health Promot 2016;30:214-23.

5. Clapp JF. Influence of endurance exercise and diet on human placental development and fetal growth. Placenta 2006;27(67):527-34.

6. Harrod CS, Chasan-Taber L, Reynolds RM, et al. Physical activity in pregnancy and neonatal body composition: the Healthy Start study. Obstet Gynecol 2014;124(2 Pt 1):257-64.

7. Clapp JF, Kim H, Burciu B, et al. Beginning regular exercise in early pregnancy: effect on fetoplacental growth. Am J Obstet Gynecol 2000;183:1484-8.

8. Badon SE, Wander PL, Qiu C, et al. Maternal leisure time physical activity and infant birth size. Epidemiology 2016;27:74-81.
9. ACOG. ACOG Committee opinion No. 650: Physical activity and exercise during pregnancy and the postpartum period. Obstet Gynecol 2015;126:e135-42.

10. Salvesen KA Hem E, Sundgot-Borgen J. Fetal wellbeing may be compromised during strenuous exercise among pregnant elite athletes. Br J Sports Med 2012;46:279-83.

11. Szymanski LM, Satin AJ. Strenuous exercise during pregnancy: is there a limit? Am J Obstet Gynecol 2012;207:179.e1-179.e6.

12. Manders MA, Sonder GJ, Mulder EJ, et al. The effects of maternal exercise on fetal heart rate and movement patterns. Early Hum Dev 199748:237-47

13. Watson WJ, Katz VL, Hackney AC, et al. Fetal responses to maximal swimming and cycling exercise during pregnancy. Obstet Gynecol 1991;77:382-6.

14. Webb KA, Wolfe LA, McGrath MJ. Effects of acute and chronic maternal exercise on fetal heart rate. J Appl Physiol 1994;77:2207-13.

15. Jukic AM, Evenson KR, Daniels JL, et al. A prospective study of the association between vigorous physical activity during pregnancy and length of gestation and birthweight. Matern Child Health $J$ 2012;16:1031-44.

16. Fraser WD, Shapiro GD, Audibert F, et al; 3D Study Group. 3D Cohort Study: the Integrated Research Network in Perinatology of Quebec and Eastern Ontario. Paediatr Perinat Epidemiol 2016;30:623-32.

17. von Elm E, Altman DG, Egger M, et al; STROBE Initiative. The Strengthening the Reporting of Observational Studies in Epidemiology (STROBE) statement: guidelines for reporting observational studies. Epidemiology 2007;18:800-4.

18. Kramer MS, Platt RW, Wen SW, et al; Fetal/Infant Health Study Group of the Canadian Perinatal Surveillance System. A new and improved population-based Canadian reference for birth weight for gestational age. Pediatrics 2001;108:E35.

19. Chasan-Taber L, Schmidt MD, Roberts DE, et al. Development and validation of a pregnancy physical activity questionnaire. Med Sci Sports Exerc 2004;36:1750-60.

20. Chandonnet N, Saey D, Alméras N, et al. French Pregnancy Physical Activity Questionnaire compared with an accelerometer cut point to classify physical activity among pregnant obese women. PLOS One 2012; $7:$ e38818

21. Ainsworth BE, Haskell WL, Herrmann SD, et al. Compendium of Physical Activities: a second update of codes and MET values. Med Sci Sports Exerc 201143:1575-81.

22. Bisson $M$, Sériès $F$, Giguère $Y$, et al. Gestational diabetes mellitus and sleep-disordered breathing. Obstet Gynecol 2014;123:634-41.

23. Facco FL, Kramer J, Ho KH, Kh H, et al. Sleep disturbances in pregnancy. Obstet Gynecol 2010;115:77-83.

24. Skouteris $\mathrm{H}$, Wertheim $\mathrm{EH}$, Germano $\mathrm{C}$, et al. Assessing sleep during pregnancy: a study across two time points examining the Pittsburgh Sleep Quality Index and associations with depressive symptoms. Womens Health Issues 2009;19:45-51.

25. Thompson D, Berger H, Feig D, et al; Canadian Diabetes Association Clinical Practice Guidelines Expert Committee. Diabetes and pregnancy. Can J Diabetes 2013; 37(Suppl 1):S168-83

26. Magee LA, Pels A, Helewa M, et al; Canadian Hypertensive Disorders of Pregnancy Working Group. Diagnosis, evaluation, and management of the hypertensive disorders of pregnancy: executive summary. J Obstet Gynaecol Can 2014;36:416-41.

27. Delaney M, Roggensack A, Leduc DC, et al; Clinical Practice Obstetrics CommitteeMaternal Fetal Medicine Committee. Guidelines for the management of pregnancy at $41+0$ to $42+0$ weeks. J Obstet Gynaecol Can 2008;30:800-10.

28. WHO. . Physical status: the use and interpretation of anthropometry. Report of a WHO Expert Committee. Geneva: World Health Organization; 1995,. WHO Technical Reports Series 854.

29. Valeri L, Vanderweele TJ. Mediation analysis allowing for exposuremediator interactions and causal interpretation: theoretica assumptions and implementation with SAS and SPSS macros. Psychol Methods 2013;18:137-50.

30. Horton NJ, Kleinman KP. Much ado about nothing: a comparison of missing data methods and software to fit incomplete data regression models. Am Stat 2007;61:79-90.

31. Rubin DB. Multiple imputation for nonresponse in surveys. New York: Wiley, 1987.

32. Davenport MH, Ruchat SM, Giroux I, et al. Timing of excessive pregnancy-related weight gain and offspring adiposity at birth. Obstet Gynecol 2013;122(2 Pt 1):255-61.

33. Bisson M, Tremblay F, St-Onge O, et al. Influence of maternal physical activity on infant's body composition. Pediatr Obes 2016. 
34. Santos S, Gaillard R, Oliveira A, et al. Associations of infant subcutaneous fat mass with total and abdominal fat mass at schoolage: the Generation R Study. Paediatr Perinat Epidemiol 2016;30:511-20.

35. Juhl M, Olsen J, Andersen PK, et al. Physical exercise during pregnancy and fetal growth measures: a study within the Danish National Birth Cohort. Am J Obstet Gynecol 2010;202:63.e1-63.e8.

36. Barakat R, Pelaez M, Cordero $\mathrm{Y}$, et al. Exercise during pregnancy protects against hypertension and macrosomia: randomized clinical trial. Am J Obstet Gynecol 2016;214:649 .e1- 649.e8.

37. Hunt KJ, Alanis MC, Johnson ER, et al. Maternal pre-pregnancy weight and gestational weight gain and their association with birthweight with a focus on racial differences. Matern Child Health $J$ 2013;17:85-94.

38. McCullough LE, Mendez MA, Miller EE, et al. Associations between prenatal physical activity, birth weight, and DNA methylation at genomically imprinted domains in a multiethnic newborn cohort. Epigenetics 2015;10:597-606.

39. Azzi S, Sas TC, Koudou Y, et al. Degree of methylation of ZAC1 (PLAGL1) is associated with prenatal and post-natal growth in healthy infants of the EDEN mother child cohort. Epigenetics 2014;9:338-45.

40. Redman CW, Sargent IL, Staff AC. IFPA Senior Award Lecture: making sense of pre-eclampsia - two placental causes of preeclampsia? Placenta 2014;35(Suppl):S20-5.
41. Hackett GA, Cohen-Overbeek T, Campbell S. The effect of exercise on uteroplacental Doppler waveforms in normal and complicated pregnancies. Obstet Gynecol 1992;79:919-23.

42. Chaddha V, Simchen MJ, Hornberger LK, et al. Fetal response to maternal exercise in pregnancies with uteroplacental insufficiency. Am J Obstet Gynecol 2005;193(3 Pt 2):995-9.

43. Aune D, Saugstad OD, Henriksen T, et al. Physical activity and the risk of preeclampsia: a systematic review and meta-analysis. Epidemiology 2014;25:331-43.

44. Wolf HT, Owe KM, Juhl M, et al. Leisure time physical activity and the risk of pre-eclampsia: a systematic review. Matern Child Health $J$ 2014:18:899-910.

45. Bo K, Artal R, Barakat R, et al. Exercise and pregnancy in recreational and elite athletes: 2016 evidence summary from the IOC expert group meeting, Lausanne. Part 1-exercise in women planning pregnancy and those who are pregnant. Br J Sports Med 2016;50:571-89.

46. Brett KE, Wilson S, Ferraro ZM, et al. Self-report Pregnancy Physical Activity Questionnaire overestimates physical activity. Can J Public Health 2015;106:e297-302.

47. Sterne JA, White IR, Carlin JB, et al. Multiple imputation for missing data in epidemiological and clinical research: potential and pitfalls. BMJ 2009;338:b2393. 